Portland State University

PDXScholar

$5-25-2018$

\title{
Cyanobacteria Ecotypes in the North Pacific
}

Samantha Ward

Portland State University

Follow this and additional works at: https://pdxscholar.library.pdx.edu/honorstheses Let us know how access to this document benefits you.

Recommended Citation

Ward, Samantha, "Cyanobacteria Ecotypes in the North Pacific" (2018). University Honors Theses. Paper 585.

https://doi.org/10.15760/honors.594

This Thesis is brought to you for free and open access. It has been accepted for inclusion in University Honors Theses by an authorized administrator of PDXScholar. Please contact us if we can make this document more accessible: pdxscholar@pdx.edu. 


\section{Portland State University PDXScholar}

\section{Cyanobacteria Ecotypes in the North Pacific}

Samantha Ward

\section{Let us know how access to this document benefits you.}

Follow this and additional works at: https://pdxscholar.library.pdx.edu/honorstheses

This Thesis is brought to you for free and open access. It has been accepted for inclusion in University Honors Theses by an authorized administrator of PDXScholar. For more information, please contact pdxscholar@pdx.edu. 


\section{Cyanobacteria Ecotypes in the North Pacific}

\section{Samantha Ward}

An undergraduate honors thesis submitted

in partial fulfillment of the requirements for the degree of

Bachelor of Science in University Honors and Biology

Thesis Advisor

Anne Thompson, PhD 
Portland State University

2018

\begin{abstract}
Phytoplankton are an essential part of nutrient cycling in the marine environment. Of particular interest are Synechococcus and Prochlorococcus, two closely-related groups of cyanobacteria that are among the most abundant photosynthetic cells on the planet. However, the environmental factors that drive evolution of these bacteria into distinct ecotypes remains poorly understood. Here, we examine cyanobacterial diversity along an understudied transect of the North Pacific Ocean. Nine surfaceseawater samples were analyzed using PCR of the Prochlorococcus ITS region and high-throughput DNA sequencing. We observed an abundance of HL-II Prochlorococcus in subtropical regions, an abundance of HL-I Prochlorococcus in temperate regions, and an abundance of Synechococcus in cooler, coastal regions. When superimposed beside the temperature gradient observed along the transect, a clear pattern emerges that suggests an important relationship between sea-surface temperature and the Prochlorococcus ecotype community structure in the North Pacific Ocean.
\end{abstract}




\section{Introduction}

Prochlorococcus accounts for an estimated 5\% of global photosynthetic activity. Due to their abundance and widespread distribution, small ecological changes in populations of Prochlorococcus could have large-scale implications for the global energy web. In order to better understand the nature of these changes, many studies have sought to examine Prochlorococcus diversity. In particular, much work has been devoted to the way Prochlorococcus lineages have partitioned into specialized high and low light "ecotypes" in the oligotrophic ocean (Bouman et al. 2006, Campbell et al. 1994, Farrant et al. 2016, Huang et al. 2012, Larkin et al. 2016, Malmstrom et al. 2010, Zwirglmaier et al. 2008). This has been accomplished through circumnavigational surface sampling (Bouman et al. 2006), repeated sampling at one location over time (Campbell et al. 1994), analyzing the bacteria's petB gene (Farrant et al. 2016), sampling across depth gradients (Huang et al. 2012), comparing the abundance of Prochlorococcus in environments with different seasonal fluctuation patterns (Malmstrom et al. 2010), and comparing ecotypes in tropical and temperate zones (Zwirglmaier et al. 2008). Together, these studies have shown that incredible diversity exists in Prochlorococcus, even at the individual cell level, that ecologically distinct ecotypes coexist, and that environmental factors driving community structure and diversity remain poorly understood.

The North Pacific Ocean has an abundance of cyanobacteria. It also has diverse oceanographic conditions, nutrient availability, and other environmental factors that could influence cyanobacteria diversification. This makes it an ideal environment for studying cyanobacteria ecotype patterns with respect to oceanographic gradients.

Here, we examine how cyanobacterial diversity changes from the open ocean to a coastal environment in the North Pacific. We examined Prochlorococcus and Synechococcus ecotypes by comparing diversity found at the $16 \mathrm{~S} / 23 \mathrm{~S}$ ITS level. Our work offers interesting insights into and 
temperature-based shifts of Prochlorococcus ecotypes in the North Pacific, leading to an improved understanding of diversity in this abundant bacterium.

\section{Materials and Methods}

\section{Oceanographic Sampling}

Filtered seawater from nine North Pacific Ocean sites was collected in March-April of 2017 aboard the R/V Sikuliaq Cruise \#SKQ201703S (Figure 1, Table 1). The latitude sampled ranges from 26.1 degrees North to 42.3 degrees North, beginning at the warm and nutrient-poor open ocean near Station ALOHA and ending at the relatively cold and nutrient-rich coastal region near Newport, OR. The samples were collected from the ship's uncontaminated flow-through seawater system, while temperature and salinity information were simultaneously collected by the Sea-Bird Scientific SBE 45 microTSG. Satellite data were acquired from the MUR SST database maintained by the California Institute of Technology.

Table 1. Locations of surface-seawater collection sites

\begin{tabular}{|c|c|c|}
\hline Sample & $\begin{array}{c}\text { Date } \\
\text { Collected }\end{array}$ & Sampling Location \\
\hline A & $3 / 9 / 2017$ & $26.0749 \mathrm{~N},-146.0189 \mathrm{~W}$ \\
\hline B & $3 / 17 / 2017$ & $30.2650 \mathrm{~N},-145.6328 \mathrm{~W}$ \\
\hline C & $3 / 30 / 2017$ & $35.2482 \mathrm{~N},-139.6439 \mathrm{~W}$ \\
\hline D & $3 / 31 / 2017$ & $36.7022 \mathrm{~N},-137.5114 \mathrm{~W}$ \\
\hline E & $3 / 31 / 2017$ & $37.2987 \mathrm{~N},-136.9502 \mathrm{~W}$ \\
\hline F & $4 / 2 / 2017$ & $41.2684 \mathrm{~N},-130.5722 \mathrm{~W}$ \\
\hline G & $4 / 2 / 2017$ & $41.2953 \mathrm{~N},-130.5758 \mathrm{~W}$ \\
\hline H & $4 / 2 / 2017$ & $41.9689 \mathrm{~N},-129.0283 \mathrm{~W}$ \\
\hline I & $4 / 2 / 2017$ & $42.3078 \mathrm{~N},-128.8542 \mathrm{~W}$ \\
\hline
\end{tabular}




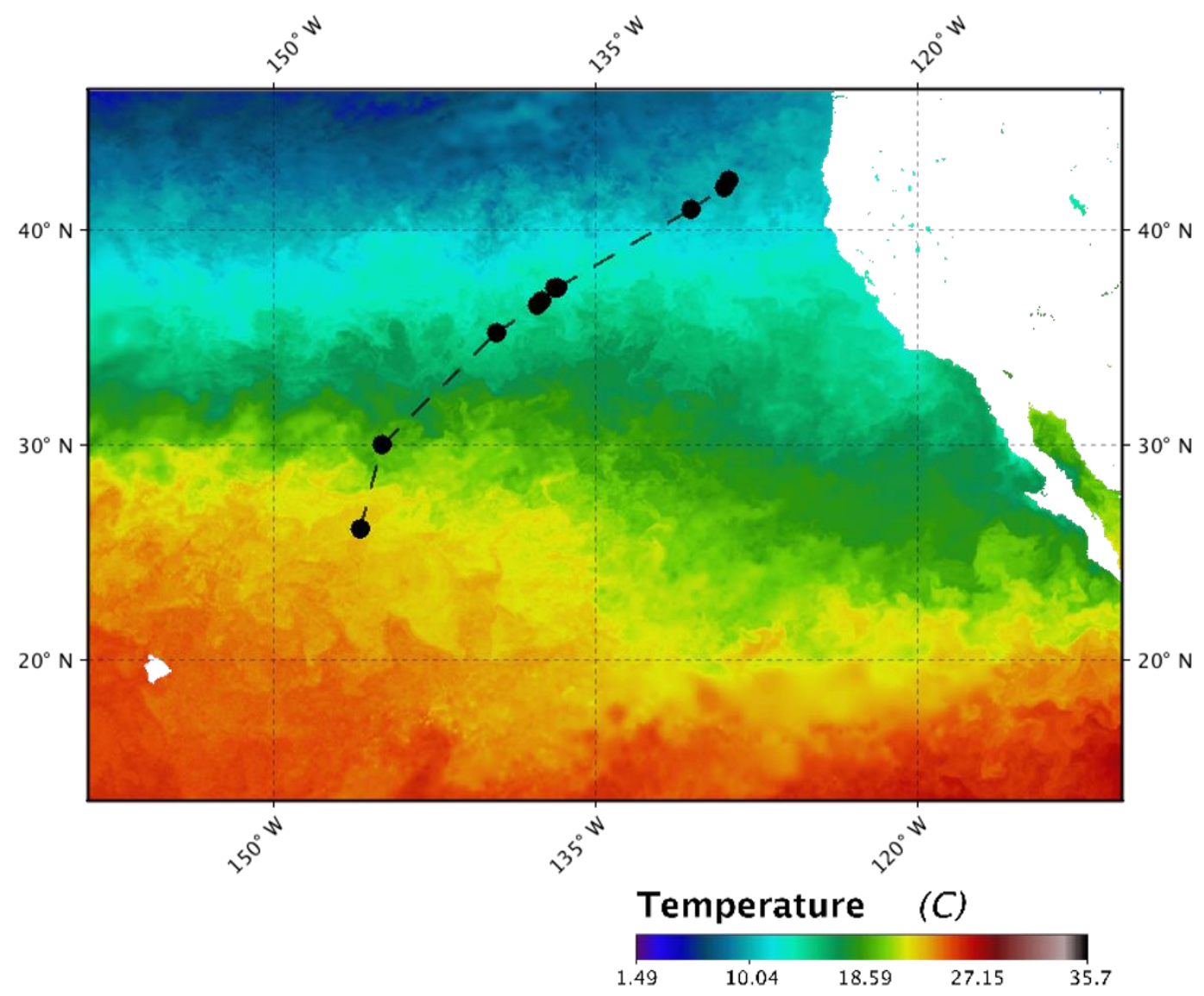

Figure 1. Sample Stations for DNA extractions depicted in context of sea surface temperatures detected by satellite in March 2017. 


\section{DNA Extraction}

$200 \mathrm{~mL}$ samples of surface seawater concentrated on Sterivex filters were stored at stored at $-80^{\circ} \mathrm{C}$ until processing. DNA was extracted using a previously described phenol:chloroform procedure (Wright et al.2009), and quantified via QuBit high sensitivity fluorometer for dsDNA (Qiagen). Extracted DNA was stored at $-20^{\circ} \mathrm{C}$.

\section{PCR of Intergenic Transcribed Spacer Region}

To amplify cyanobacterial DNA, PCR was performed on the ITS region of the samples ranging in concentration from $2 \mu \mathrm{M}-20 \mu \mathrm{M}$ and using Illumina-adapted and barcoded primers described by Nathan Ahlgren (N. Ahlgren, personal communication, May 2018) (Table 2). The PCR was performed using the following program: initial denaturation at $94^{\circ} \mathrm{C}$ for 2 minutes, followed by 30 cycles of $94^{\circ} \mathrm{C}$ for 20 seconds, $55^{\circ} \mathrm{C}$ for 20 seconds, $65^{\circ} \mathrm{C}$ for $1 \mathrm{~min}$, and a final extension at $65^{\circ} \mathrm{C}$ for two minutes. Bands of approximately $550 \mathrm{bp}$ in length were excised from agarose gel, and purified using the Invitogen PureLink Quick Gel Extraction kit. Amplicons with the barcodes were pooled before sequencing.

Table 2. Cyanobacterial-specific 16S/23S ITS Primers used in this study (N. Ahlgren, personal communication, May 2018).

\begin{tabular}{|l|l|}
\hline Primer Type & Sequence $\left(5^{\prime}\right.$ to $\left.3^{\prime}\right)$ \\
\hline Forward & CGTACTACAATGCTACGG \\
\hline Reverse & GGACCTCACCCTTATCAGGG \\
\hline
\end{tabular}

\section{Sequencing and Bioinformatic Processing}

The samples were sent for Illumina MiSeq high throughput DNA sequencing at the OSU Center for Genome Research and Biocomputing, using 2×250 bp reads. Samples were demultiplexed by barcodes on reverse reads at the sequencing facility. The QIIME pipeline was used to quality filter the raw 
sequence data $(Q>30)$, demultiplex the reads with the forward barcode, and call operational taxonomic units (OTUs) (for description of QIIME scripts, see supplementary information). A representative sequence for each OTU was selected and identified using BLAST (Altschul et al. 1997).

\section{Results}

Diversity and Distribution

Site 'A' exhibited the greatest diversity of the samples studied, with 'minority-type' OTUs (OTUs besides the three most abundant OTUs, see Figure 3 ) contributing to approximately $46.0 \%$ of OTU representation. In contrast, sites C, D, and E exhibited the least diversity, with minority OTUs providing only $8.0-9.3 \%$ of overall OTU coverage.

The top 3 OTUs identities (Figure 3) were determined to most closely resemble the organisms Synechococcus sp. CC9902 (BLAST accession number CP000097.1), Prochlorococcus marinus subsp. pastoris str. CCMP1986 (BLAST accession number BX548174.1), and Prochlorococcus sp. RS04 (BLAST accession number CP018346.1). Prochlorococcus marinus subsp. pastoris str. CCMP1986 is a HL-I ecotype of Prochlorococcus, and Prochlorococcus sp. RSO4 is a HL-Il ecotype of Prochlorococcus. 


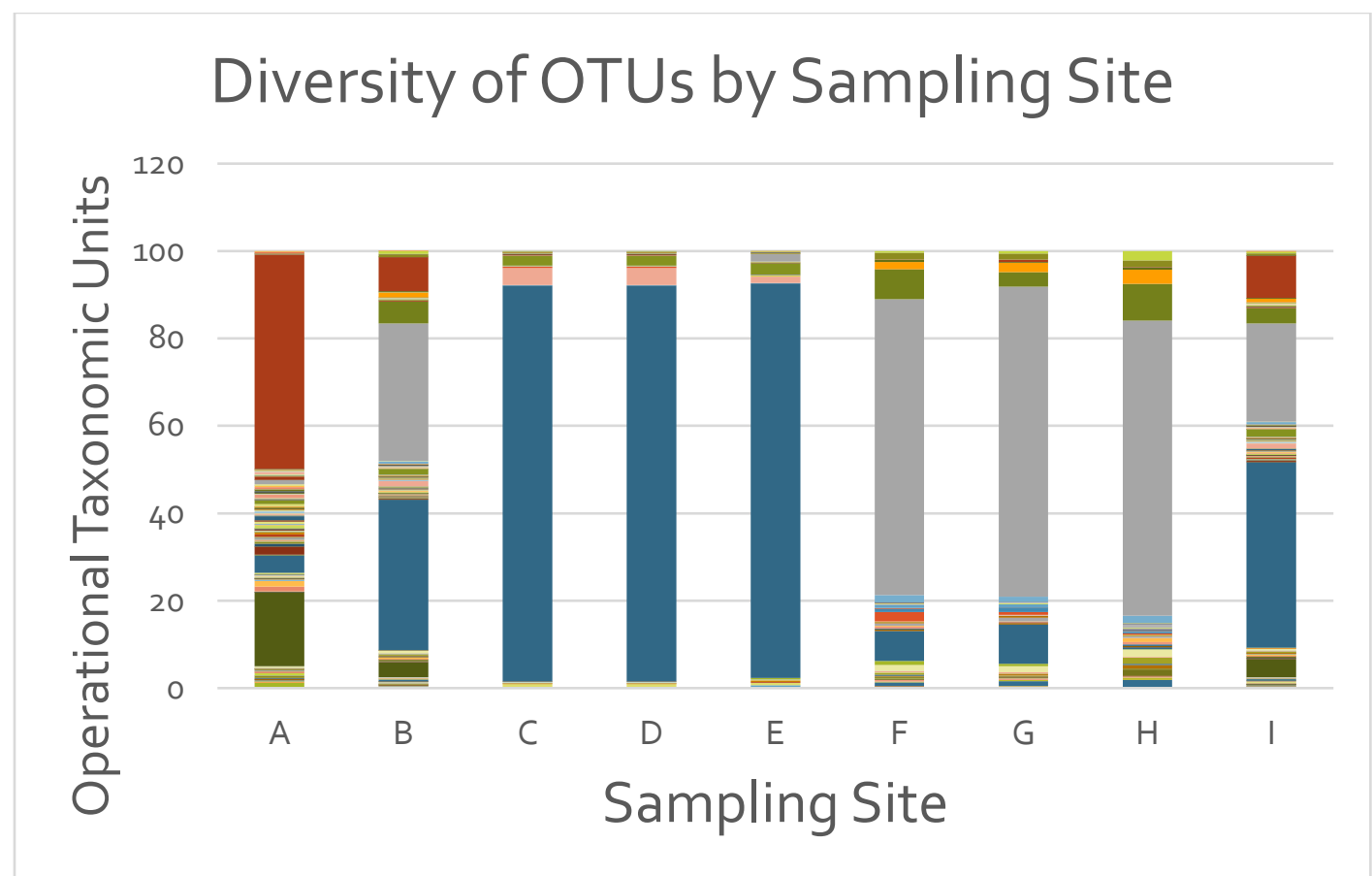

Figure 2. Site ' $A$ ' exhibits the greatest diversity of all the samples studied. Sites ' $C$ ', ' $D$ ', and ' $E$ ' exhibit the least diversity. 


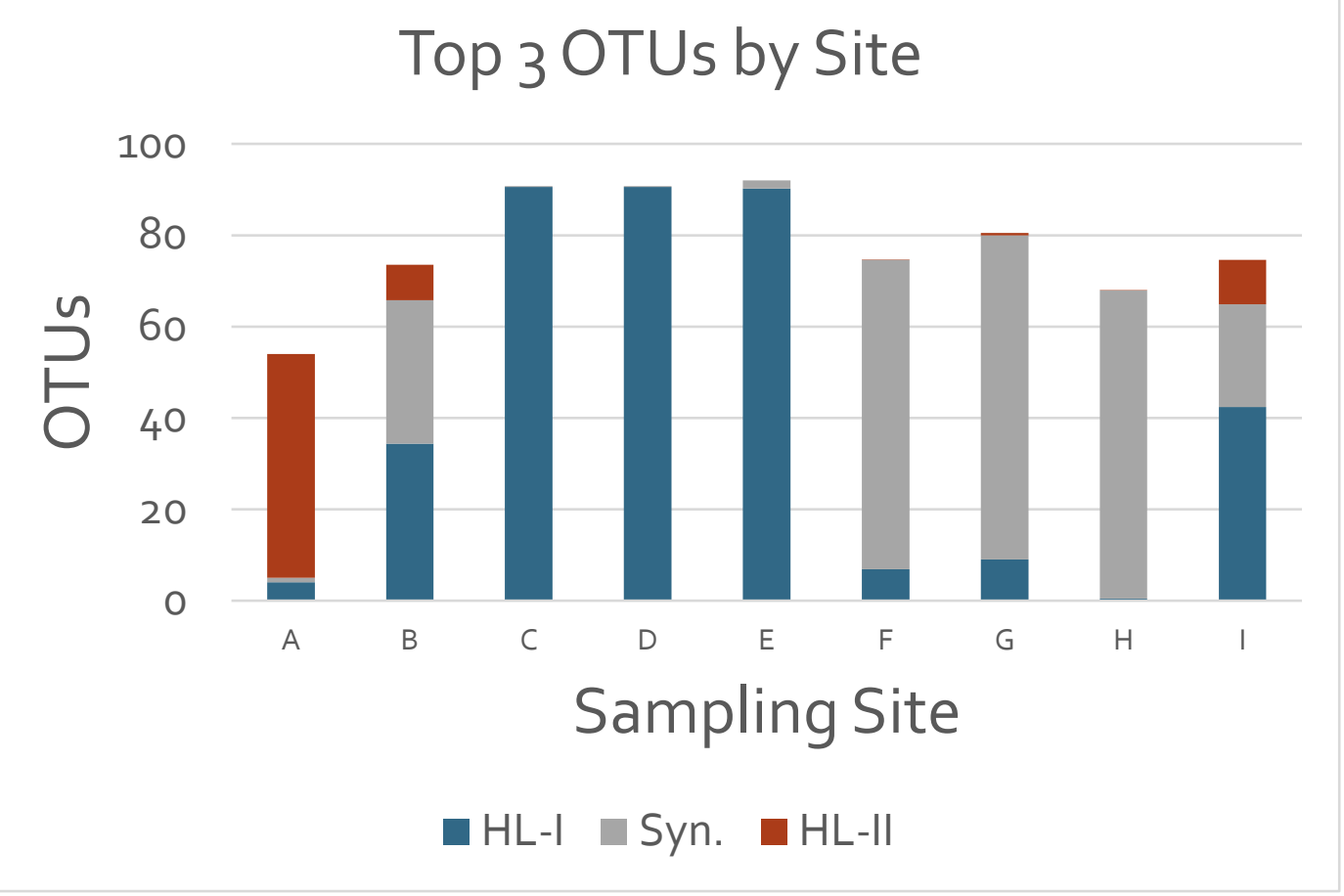

Figure 3. The top 3 most abundant OTUs were plotted with respect to distribution across the transect. The transect begins with an abundance of Prochlorococcus marinus subsp. pastoris str. CCMP1986 (HL-II) at site 'A', followed by a more diverse distribution at site ' $\mathrm{B}$ ', an abundance of Prochlorococcus sp. RSO4 (HL-I) at sites ' $\mathrm{C}$ '-' $\mathrm{E}$ ', an abundance of Synechococcus sp. CC9902 (Syn.) at sites ' $F$ ' - ' $H$ ', and a final diverse distribution at site ' $I$ '. 


\section{OTU Abundance vs. Temperature}

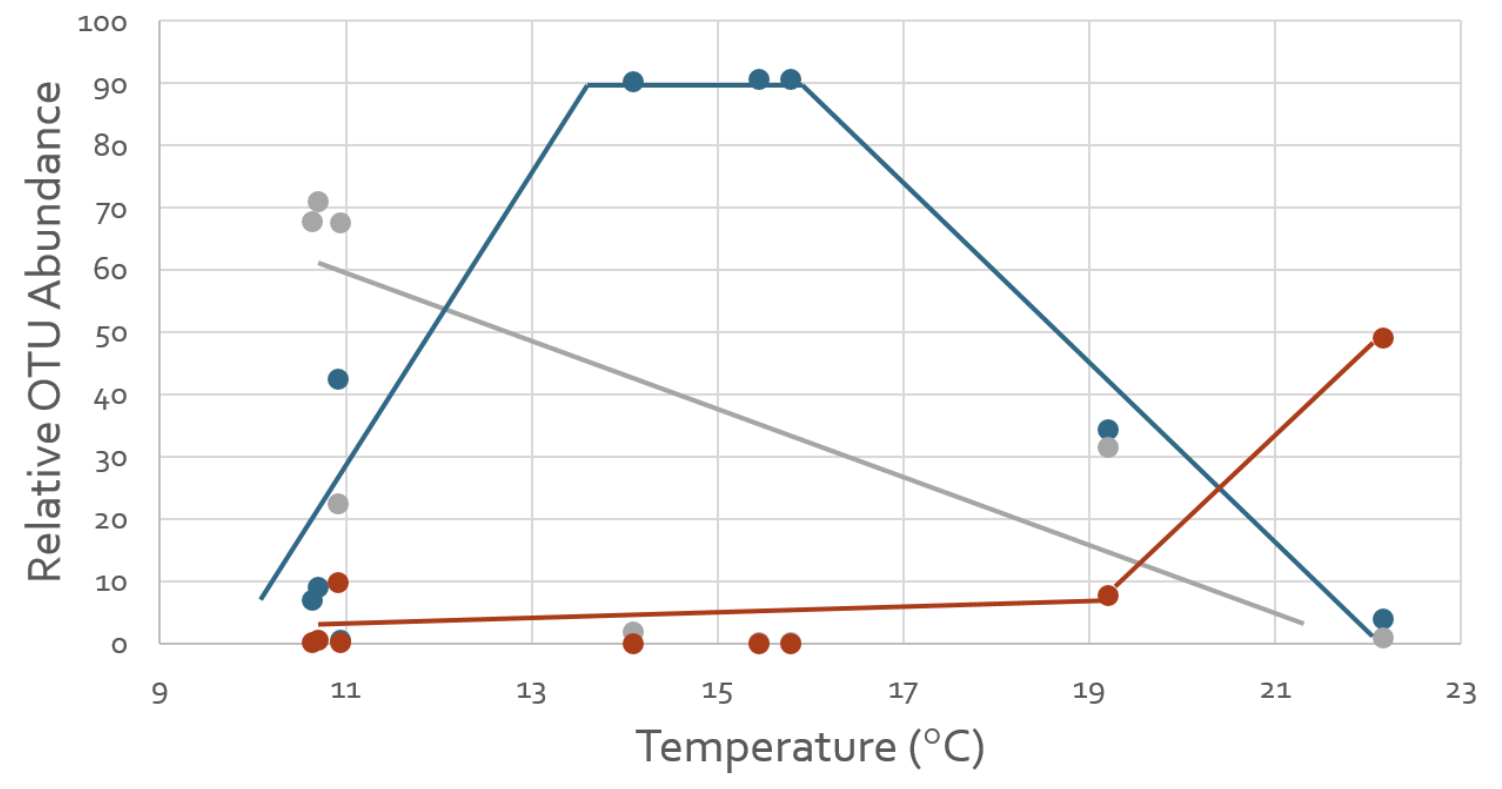

- HL-I • Syn. • HL-II

Figure 3. Three trends become apparent when inspecting OTU abundance with respect to temperature. 1) HL-II ecotypes along the transect are more abundant at higher temperatures. 2) Synechococcus abundance becomes more abundant at cooler temperatures along the transect. 3) HL-I ecotypes occupy an intermediate temperature range compared to the other two. (Trendlines drawn by eye.) 


\section{OTU Abundance vs. Salinity}

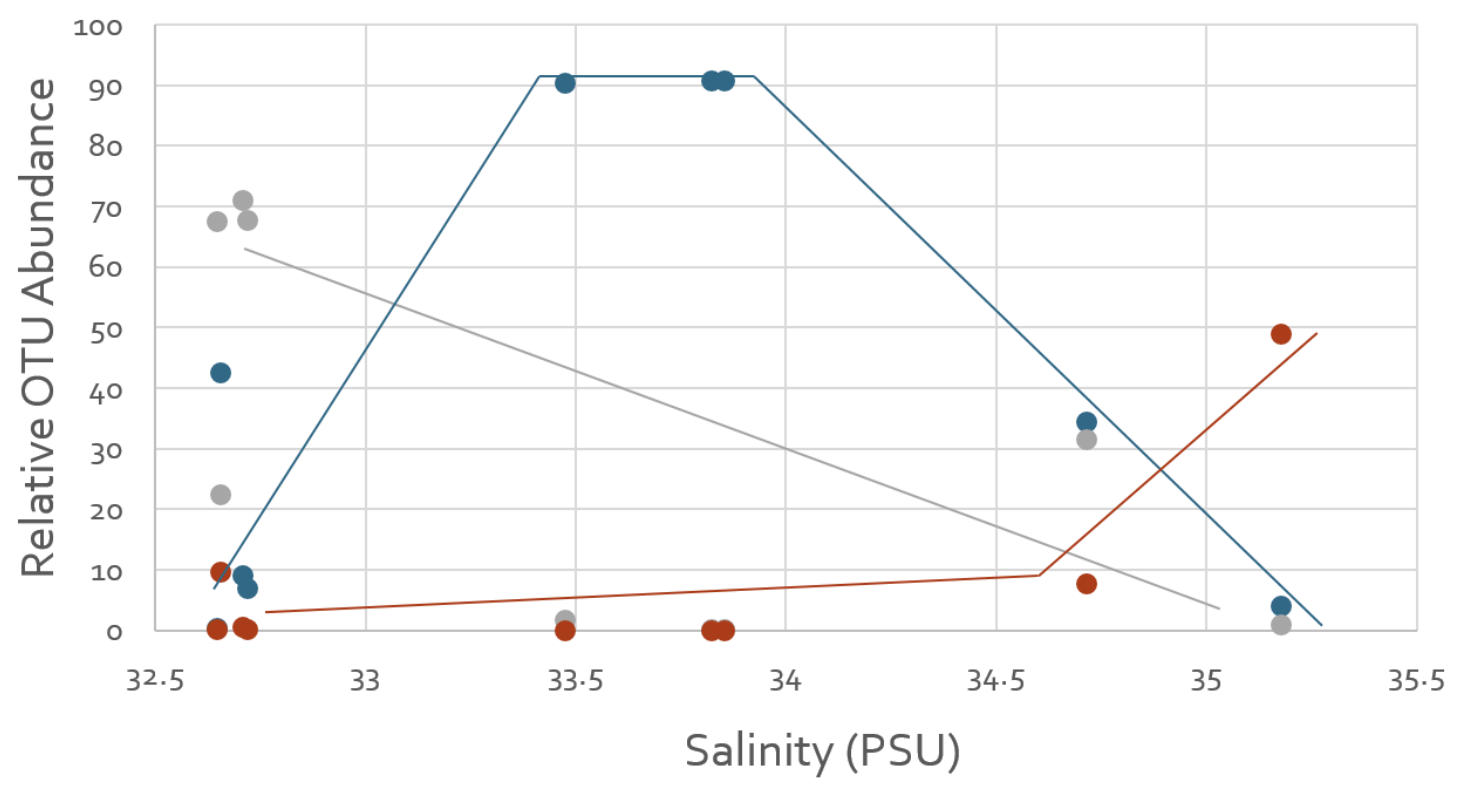

- HL-I • Syn. • HL-II

Figure 4. The trends for salinity closely mirror the trends for temperature (see Figure 4). (Trendlines drawn by eye) 


\section{Discussion}

We explored the diversity of cyanobacteria types present along a transect of the North Pacific. Distinct patterns emerged with respect to temperature. For example, a majority abundance of Prochlorococcus was dramatically replaced with a majority abundance of Synechococcus as the sampling approached the Oregon coast. This transition occurred at the point in the transect where the surface temperature ranged from around $11-13^{\circ} \mathrm{C}$ (Figure 3). This is consistent with previous reports of Prochlorococcus thriving in oligotrophic conditions and declining in more nutrient-rich waters (Bouman et al. 2006). Most Prochlorococcus cyanobacteria are not known to use nitrate (Bouman et al. 2006), but most Synechococcus cyanobacteria are, suggesting that the availability of organic nitrate to organisms that graze on cyanobacterial might be increased in the colder, more nutrient-rich waters where Synechococcus dominate.

Zwirglmaier et al. found that HL-II ecotypes tend to be more abundant at subtropical and tropical zones, while HL-I ecotypes tend to be more abundant at temperate zones. This trend was also described in Johnson et al. 2006, where eMED4 (a HL-I ecotype) abundance was found to dominate cooler, high latitude waters. Similarly, our data showed an abundance of HL-II ecotypes present at 'Site $\mathrm{A}^{\prime}$, corresponding to a subtropical latitude of $26.1^{\circ} \mathrm{N}$ (Table 1 ), and a clear abundance of HL-I ecotypes emerging at 'Site $\mathrm{C}^{\prime}$, corresponding to a more temperate latitude of $35.2^{\circ} \mathrm{N}$. The ecological impacts of an abundance of $\mathrm{HL}-\mathrm{I}$ or HL-Il ecotypes is being examined presently with respect to differences in carbon fixation and nutrient cycling. For example, it has been demonstrated that there are novel HL-I strainspecific genes that confer a stress response to phosphate starvation (Martiny et al. 2006), and other high-light ecotypes with increased iron-scavenging abilities (Malmstrom et. al 2013), already suggesting that different high-light ecotypes interact with trace nutrients in the ecosystem differently. 
Our study is limited by an unequal distribution of reads across the transect. For example, we were able to get a tenfold increase in the number of reads at 'Site $A$ ' compared to the number of reads we were able to get at 'Site E'. Although all data presented was normalized with respect to the number of reads per site, the diversity trends at the sites with the least coverage ( $D E, J$, and $H$ ) may not be as representative of the area sampled as the remaining sites that received a higher degree of coverage.

Because there were distinct trends with respect to the ecotypes and the gradients examined, temperature and salinity may help explain the ecotypical changes observed in the North Pacific. Future study of this transect should also examine the relationship of day length, silicate, oxygen, phosphate, and chlorophyll conditions with observed ecotypes, as these were demonstrated to be significant drivers of cyanobacterial community composition change (Larkin et al. 2016). It should also be noted that salinity was not found to be a significant driver of ecotype shifts in the Larkin et al. study, and was "merely correlated with large-scale oceanographic trends" (Larkin et al. 2016). As such, it is possible that our observed trends with respect to salinity are simply correlated to, and not a causative agent of cyanobacteria ecotype change. Additional future work might consist of conducting a phylogenetic analysis of the OTUs observed along the transect and comparing the resulting cladogram to similar analysis conducted in other studies, as in Larkin et al. 2016.

Overall, the data presented in our study suggest that temperature is an important ecological driver of cyanobacteria OTU diversification. We observed an abundance of HL-II Prochlorococcus in subtropical regions, an abundance of $\mathrm{HL}-\mathrm{I}$ Prochlorococcus in temperate regions, and an abundance of Synechococcus in cooler, coastal regions. Other oceanic conditions might be explored along this transect to gain a better understand of the factors that drive the evolutionary partitioning of this globally important and very abundant organism. 


\section{Acknowledgements}

We thank the officers, crew, and scientists of the $R / V$ Sikuliaq during cruise number SKQ201703s in March 2017. Funding was provided by the National Science Foundation (award OCE-1646709 to Thompson).

A special thank you to Kate Kouba and Dr. Anne Thompson for mentorship throughout the research process. 


\section{References}

1. Altschul, S. F., Madden, T.L., Schaffer, A. A.et al. "Gapped BLAST and PSIBLAST: A new generation of protein database search programs." (1997). Nucleic Acids Res. 25 3389-3402.

2. Bouman,Heather A., Osvaldo Ulloa, David J. Scanlan, Katrin ZwirgImaier, William K. W. Li, Trevor Platt, Venetia Stuart, Ray Barlow, Ole Leth, Lesley Clementson, Vivian Lutz, Masao Fukasawa, Shuichi Watanabe, and Shubha Sathyendranath. "Oceanographic Basis of the Global Surface Distribution of Prochlorococcus Ecotypes." (2006). Science 312 918-921.

3. Campbell L, Liu HB, Nolla HA, Vaulot D. "The Importance of Prochlorococcus to Community Structure in the Central North Pacific Ocean." Limnol Oceanogr 39 (1994) 954-961.

4. Coleman, Maureen L. and Sally Chisholm. "Code and Context: Prochlorococcus as a Model for Cross-Scale Biology." (2007) Elsevier Ltd. 15(9) 398-407.

5. Farrant, Gregory, Hugo Dore, Francisco Cornejo-Castillo, Frederic Partensky, Morgane Ratin, Martin Ostrowski, Frances Pitt, Patrick Wincker, David Scanlan, Daniele Ludicone, Silvia Acinas, Laurence Garczarek. "Delineating ecologically significant taxonomic units from global patterns of marine picocyanobacteria." PNAS (2016) E3365-E3374.

6. Huang, Sijun, Steven Wilhelm, H Roger Harvey, Karen Taylor, Nianzhi Jiao, and Feng Chen. "Novel lineages of Prochlorococcus and Synechococcus in the global oceans." The ISME Journal 6 (2012) 285-297.

7. Larkin, Alyse A, Sara K Blinebry, Caroline Howes, Yajuan Lin, Sarah E Loftus, Carrie A Schmaus, Eric R Zinser, and Zachary I Johnson. "Niche Partitioning and Biogeography of High Light Adapted Prochlorococcus Across Taxonomic Ranks in the North Pacific." International Journal for Microbial Ecology 10 (2016). 1555-1567.

8. Malmstrom, Rex, Allison Coe, Gregory Kettler, Adam Martiny, Jorge Frias-Lopez, Erik Zinser, Sallie Chisholm. "Temporal dynamics of Prochlorococcus ecotypes in the Atlantic and Pacific oceans." The ISME Journal 4 (2010) 1252-1264.

9. Malmstrom, Rex, Sébastien Rodrigue, Katherine Huang, Libusha Kelly, Suzanne Kern, Anne Thompson, et al. "Ecology of uncultured Prochlorococcus clades revealed through single-cell genomics and biogeographic analysis." The ISME Journal 7 (2013) 184-198.

10. Martiny, Adam, Maureen Coleman, and Sallie Chisholm. "Phosphate acquisition genes in Prochlorococcus ecotypes: Evidence for genome-wide adaptation." PNAS 103(33) (2006) 1255212557. 
11. Moore, Lisa, Allison Coe, Erik Zinser, Saito Matthew, Debbie Lindell, Katya Frois-Moniz, John Waterbury, and Sally Chisholm. "Culturing the marine cyanobacterium Prochlorococcus." Linnol: Oceanogr: Methods 5 (2007) 353-362.

12. Wright, JJ, Lee $S$, Zaikova E, Walsh DA, Hallam SJ. "DNA Extraction from $0.22 \mu \mathrm{M}$ Sterivex Filters and Cesium Chloride Density Gradient Centrifugation." Journal of Visualized Experiments 31 (2009) 1352.

13. Zwirglmaier, Katrin, Ludwig Jardillier, Martin Ostrowski, Sophie Mazard, Laurence Garczarek, Daniel Vaulot, Fabrice Not, Ramon Massana, Osvaldo Ulloa, and Dave J. Scanlan. "Global phylogeography of marine Synechococcus and Prochlorococcus reveals a distinct partitioning of lineages among oceanic biomes". Environmental Microbiology 10(1) (2008) 147161. 


\section{Supplementary Information}

QIIME Scripts Work-Flow for Bioinformatic Analysis

\#validate mapping files

validate_mapping_file.py -o vmf-map/ -m miseq122017_FWD_barcodes_R01.txt

Trim the forward reads to remove the variable ' 4 N' nucleotides.

\# get barcodes from the forward reads (R1) of all samples (that were already separated by RVS barcodes at sequencing facility)

extract_barcodes.py -f /path.fastq -o path -c barcode_single_end -I 5

\# split raw R2s based on fwd barcodes and quality filter (default errors in barcode)

split_libraries_fastq.py -o path -i path.fastq -b path/barcodes.fastq -m miSeq122017_FWD_barcodes_R01.txt --barcode_type 5 --rev_comp_mapping_barcodes --rev_comp_barcode -q 30 -n 0

\# take fasta files from split library and check for "barcode on reverse reads", write only sequences that contain perfect match to RVS primer

\#\# files names will now have Unique Sample ID from split_libraries_fastq preceded by "RVSYes" from

split_libraries...

split_libraries.py -m Rprimer_map.txt -f /path/seqs.fna -o/path/ --barcode_type 20 -e 0 --disable_primers

Remove "RVSYes" from fasta sequence names.

Concatenate all sequences and rename with .fna.

\# OTU picking

\#pick OTUs denovo, best for when no reference database then summarize output

pick_de_novo_otus.py

biom convert

biom summarize-table

\# filter OTU table to remove all OTUs that do not contain at least 100 sequences then convert from biom format to summary and text file.

filter_otus_from_otu_table.py

biom convert

hinm summarize-table 